\title{
Dopamine Release in the Dorsal Striatum during Cocaine-Seeking Behavior under the Control of a Drug-Associated Cue
}

\author{
Rutsuko Ito, Jeffrey W. Dalley, Trevor W. Robbins, and Barry J. Everitt \\ Department of Experimental Psychology, University of Cambridge, Cambridge, CB2 3EB, United Kingdom
}

Compulsive drug use is characterized by a pattern of drug seeking and consumption that becomes progressively habitual and less and less modifiable by external and internal factors. Although traditional views would posit that nigrostriatal dopamine (DA) neurons originating in the substantia nigra and innervating the dorsal striatum are primarily concerned with motor functions, recent studies have implicated the dorsal striatum in mediating stimulus-response (habit) learning. In this study, in vivo microdialysis in combination with a second-order schedule of cocaine reinforcement was used to investigate the role of the dorsal striatal dopamine innervation in well established drugseeking behavior under the control of a drug-associated cue [light conditioned stimulus (CS+)]. Rats were initially trained to self-administer cocaine under a continuous reinforcement schedule where a response on one of two identical levers led to a $20 \mathrm{sec}$ presentation of a light CS+ and an intravenous cocaine infusion $(0.75 \mathrm{mg} / \mathrm{kg})$. The response requirement for the CS + and cocaine was then progressively increased until stable responding was established under a second-order schedule of reinforcement. During microdialysis, rats were presented with the cocaine-associated CS+ either noncontingently or contingent on responding during a session of cocaineseeking behavior. The results showed a marked increase in DA release in the dorsal striatum during drug-seeking, when cocaine cues were presented contingently, but not when the same cue was presented noncontingently. These data indicate a possible involvement of the dopaminergic innervation of the dorsal striatum in well established, or habitual, cocaine-seeking behavior.

Key words: cocaine; dopamine; dorsal striatum; secondorder schedule; habit; rat; microdialysis
Compulsive drug use is associated with a pattern of drug seeking and taking that is highly stimulus-bound (Edwards and Gross, 1976; Tiffany and Carter, 1998). In humans, exposure to drug cues can evoke automatic conditioned physiological responses, selfreported craving or withdrawal, and can also motivate drugseeking behavior (Childress et al., 1988, 1993; Niaura et al., 1988; O'Brien et al., 1988). Most striking is the persistence of such behavior in the face of adverse health and social consequences (Leshner, 1997; O’Brien et al., 1998), even after a long period of abstinence (O'Brien, 1997). Such observations highlight the automated or habitual nature of persistent drug taking in addicted individuals and thus, the notion that control over drug-seeking behavior may gradually devolve to a habit system in the brain (Altman et al., 1996; Robbins and Everitt, 1999).

The dorsal striatum and its dopaminergic innervation are strongly implicated in mediating stimulus-response (S-R) habit formation (Mishkin et al., 1984; White, 1989). For example, lesions of the dorsal striatum or its dopamine (DA) innervation impair conditional rule learning in rats (Robbins et al., 1990; Reading et al., 1991), and post-trial intra-caudate administration of DA receptor agonists enhances learning of some forms of habitual behavior (Packard and White, 1991).

In a recent study, we showed that the noncontingent presentation of a cocaine-associated conditioned stimulus ( $\mathrm{CS}+$ ) mark-

\footnotetext{
Received March 1, 2002; revised April 26, 2002; accepted April 30, 2002.

This work was supported by Medical Research Council (MRC) program Grant G9537855 (B.J.E, T.W.R) and an MRC cooperative in Brain, Behavior, and Neuropsychiatry. R.I. was supported by an MRC studentship.

Correspondence should be addressed to Professor B. J. Everitt, Department of Experimental Psychology, University of Cambridge, Downing Street, Cambridge, CB2 3EB UK. E-mail: bje10@cus.cam.ac.uk.

Copyright (C) 2002 Society for Neuroscience $\quad 0270-6474 / 02 / 226247-07 \$ 15.00 / 0$
}

edly increased extracellular levels of DA selectively in the nucleus accumbens (NAcc) core, whereas presentation of the same CS+ contingent on cocaine-seeking responses did not increase DA in either the NAcc core or shell subregions (Ito et al., 2000). The failure to find a dopaminergic correlate of cocaine-seeking behavior in the NAcc was hypothesized to result from the development of a stimulus-response habit, no longer under a NAcc dopaminergic influence, as a consequence of both extended training and increasing response-reinforcer ratios supported by intermittent presentations of cocaine-associated conditioned reinforcers, which are major features of second-order schedules of cocaine reinforcement. The present study therefore tested the hypothesis that the dorsal striatal DA system, which has been implicated in stimulus-response learning, may contribute to the performance of a drug-seeking habit sustained by conditioned reinforcers, using identical procedures to those used previously (Ito et al., 2000), namely, a second-order schedule of cocaine reinforcement combined with in vivo microdialysis.

\section{MATERIALS AND METHODS}

Animals. Male Lister hooded rats (Charles River, Kent, UK) weighing between 290 and $360 \mathrm{gm}$ at the beginning of the experiment, were housed in pairs and then individually after surgery, under a reversed $12 \mathrm{hr}$ light/dark cycle (lights off 8:00 A.M.). Water was available ad libitum, and food was made available immediately after a training session. Each animal received $20 \mathrm{gm}$ of Purina laboratory chow per day, sufficient to maintain preoperative body weight and growth. All experimental sessions were performed during the dark phase, between 9:00 A.M. and 9:00 P.M., in accordance with the 1986 Animals (Scientific Procedures) Act Project License No 80/1324.

Intracerebral cannulation surgery. Animals were anesthetized with Avertin [10 gm 99\% of 2,2,2-tribromoethanol, (Sigma, Dorset, UK) in 5 mg of tertiary amyl alcohol and $4.5 \mathrm{ml}$ of PBS (Dulbecco "A"; Unipath Ltd., Basingstoke, Hampshire, UK) in $40 \mathrm{ml}$ of absolute alcohol; 1 


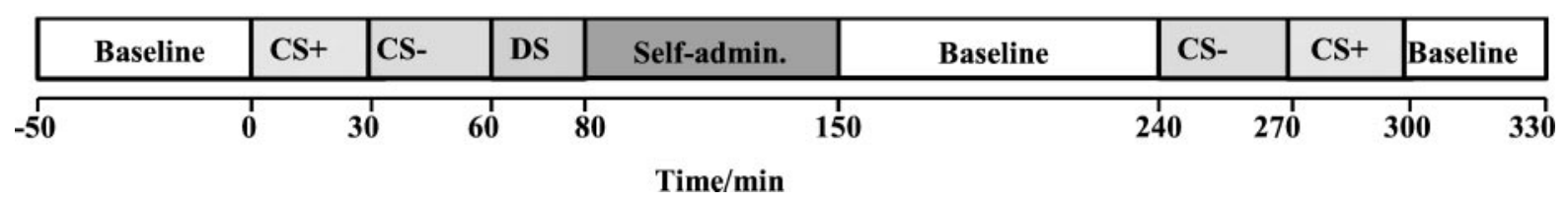

Figure 1. A schematic diagram of the sampling protocol used in the dialysis test day. Periods $-60-0,150-240,300-330$ min represent baseline sample collection: 0-30 and 270-300 min denote noncontingent light CS + presentations; 30-60 and 240-270 min represent neutral clicker (CS-) presentations; 60-80 min $(D S)$ represents drug-free cocaine-seeking period; and 80-150 min represents cocaine self-administration under the FI20 min (FR10:S) schedule of reinforcement. The whole session lasted $390 \mathrm{~min}$.

$\mathrm{ml} / 100$ gm body weight, i.p.]. A guide cannula (BAS Technicol, Congleton, Cheshire, UK) was then lowered and positioned above the dorsolateral striatum (anteroposterior +1.2 ; lateral \pm 3.1 ; dorsoventral -1.4 $\mathrm{mm}$ from bregma) and secured to the skull using dental cement, anchored by four stainless steel screws (BAS Technicol). A removable stainless steel stylet, cut flush with the tip of the cannula, was placed inside the cannula to maintain its patency throughout the training period.

Intravenous catheterization. After stereotaxic surgery, rats were allowed a recovery period of at least $5 \mathrm{~d}$ with food available ad libitum. They were then anesthetized with Avertin and implanted with a chronic intravenous jugular catheter as described previously (Caine et al., 1992). The catheter was inserted into the right jugular vein, secured in place by a suture and superglue, and then passed subcutaneously over the right shoulder to exit dorsally between the scapulas. Antibiotic treatment (daily subcutaneous administration of $0.1 \mathrm{ml}$ of Baytrill; VetDrug, Dunnington, UK) was given for $5 \mathrm{~d}$ after surgery. Thereafter, before each self-administration session, the animals were flushed with $0.1 \mathrm{ml}$ of sterile $0.9 \%$ saline and at the end of the session with $0.1 \mathrm{ml}$ of heparinized saline (CP Pharmaceuticals Ltd., Wrexham, UK; $30 \mathrm{U} / \mathrm{ml} 0.9 \%$ sterile saline) to maintain catheter patency.

Apparatus. Six operant chambers $(24-\mathrm{cm}$-wide $\times 20$-cm-high $\times 22-\mathrm{cm}-$ deep; Med Associates, St. Albans, UK) contained within a soundattenuating box with a ventilating fan were used in the experiment. Each chamber contained a side wall with two 4-cm-wide retractable levers, positioned equidistantly, $10 \mathrm{~cm}$ apart and $5 \mathrm{~cm}$ from the grid floor. Placed $3 \mathrm{~cm}$ above each lever was a round disc $(2 \mathrm{~cm}$ diameter $)$ that could be illuminated by a $2.5 \mathrm{~W}, 24 \mathrm{~V}$ light bulb, which served as a stimulus light. The whole chamber was illuminated by a red $1.8 \mathrm{~W}, 17 \mathrm{~V}$ house light positioned at the top right corner of the chamber. The chamber was also equipped with a tone generator (RS Components, Northants, UK) located centrally above the two levers. Intravenous infusions of cocaine were delivered by a software-operated infusion pump (Semat Technical Ltd., St. Albans, UK) placed outside the sound-attenuating box, through a counterbalanced single-channel liquid swivel. Animals were tethered to the counterbalanced arm via a metal spring and a skull-mounted plastic post. The apparatus was controlled by an Acorn Archimedes microcomputer (Acorn Computers Ltd, Cambridge, UK) running a program written in the BASIC control language Arachnid (Paul Fray Limited, Cambridge, UK).

Drugs. Cocaine hydrochloride (McFarlan-Smith, Edinburgh, UK) was dissolved in sterile $0.9 \%$ saline. The dose of cocaine was calculated as the salt.

Self-administration training. Each session was initiated manually by three rapid presses by the experimenter on one of the two levers, thereby designating the active or drug lever, as opposed to the second, inactive lever on which responding had no programmed consequence. These presses on the active lever had no consequence other than the initiation of the session, and no drug priming was given at any stage of training. The active and inactive levers were counterbalanced across rats. The beginning of the session was also marked by illumination of the house light. Subsequent depression of the active lever resulted in the retraction of both levers, extinction of the house light, and simultaneous illumination of the drug stimulus light for $20 \mathrm{sec}$, and also the activation of an infusion pump for $4 \mathrm{sec}$, delivering $0.1 \mathrm{ml}$ of intravenous infusion of cocaine solution $(0.25 \mathrm{mg} /$ infusion $)$. On completion of the $20 \mathrm{sec} \mathrm{CS}+$ presentation/time out period, the levers were re-extended, the house light was illuminated, and the stimulus light was extinguished. Further active lever presses resulted in the same sequence of events leading to cocaine infusions.

Animals first acquired cocaine self-administration under a continuous reinforcement schedule [fixed ratio 1 (FR1)] during daily $2 \mathrm{hr}$ sessions. Once stable rates of self-administration had been established over $10 \mathrm{~d}$, a second-order $\mathrm{FR} x(\mathrm{FR} y: \mathrm{S})$ schedule of cocaine reinforcement was introduced. Under this schedule, rats were required to make $y$ responses to obtain a single presentation of a 2 sec light CS + (or conditioned reinforcer), whereas completion of $x$ of these response units resulted in the delivery of cocaine, the illumination of the light CS + for $20 \mathrm{sec}$, the retraction of both levers, and extinction of the house light during a $20 \mathrm{sec}$ time out period. In the initial stage of training, $x$ was set at 5, whereas $y$ was 1 . The value for $x$ was then increased to 10 and remained at this value throughout the training. The value for $y$ was progressively increased from 1 to 10 until stable responding was established at FR10(FR10:S). At this stage, a $2 \mathrm{hr}$ delay period before each daily session was gradually introduced over $10 \mathrm{~d}$ for the rats to become accustomed to the baseline collection period during the dialysis experiment. Furthermore, for $3 \mathrm{~d}$ before the test day, rats were pre-exposed to noncontingent presentations of a clicker stimulus, which was subsequently used as a nondrug-paired stimulus $(\mathrm{CS}-$ ) during the microdialysis procedure.

In vivo microdialysis. A $2 \mathrm{~mm}$ microdialysis probe (21 gauge; BAS Technicol, Congleton, Cheshire, UK) was lowered into the dorsal striatum via the guide cannula $\sim 20 \mathrm{hr}$ before the start of the experiment such that the tip of the probe was positioned $5.6 \mathrm{~mm}$ vertical to dura. The inlet and outlet cannulas of the probe were then sealed with tygon stoppers, and the animals were returned to their home cages. On the test day, the probe was continuously perfused with artificial CSF (aCSF) (in mM: 147 $\mathrm{NaCl}, 3 \mathrm{KCl}, 1.3 \mathrm{CaCl}_{2}, 1 \mathrm{MgCl}_{2}, 0.2 \mathrm{NaH}_{2} \mathrm{PO}_{4}$, and $1.3 \mathrm{Na}_{2} \mathrm{HPO}_{4}, \mathrm{pH}$ 7.4) at a rate of $2 \mu \mathrm{l} / \mathrm{min}$. The volume of the outlet was kept to a minimum by using FEP tubing (Biotechnology Instruments Ltd., Kimpton, $\mathrm{UK}$; volume $1.2 \mu \mathrm{l} / 10 \mathrm{~cm}$ ) and a low dead volume three-channel liquid swivel (Biotech Instruments Ltd, UK; Channel 1: $\sim 0 \mu \mathrm{l}$, used to collect the dialysate; Channel 2: $0.32 \mu \mathrm{l}$, used to deliver the perfusate; Channel 3: $0.6 \mu \mathrm{l}$, used as the drug line). The approximate dead volume of the outlet line was $7.8 \mu \mathrm{l}$, and thus there was a time lag of $3.5 \mathrm{~min}$ (flow rate: $2 \mu \mathrm{l} / \mathrm{min}$ ) in sample collection to correct for this.

After a 60 min equilibration period, $6 \times 10 \mathrm{~min}$ baseline samples were collected in plastic vials using a peltier-cooled sample collector (Univentor-820 microsampler, Biotech Instruments Ltd, UK) (Fig. 1). For the next three $10 \mathrm{~min}$ samples, the rats received five noncontingent $10 \mathrm{sec}$ light $\mathrm{CS}+$ presentations at $1 \mathrm{~min}$ intervals starting at $50 \mathrm{sec}$ into the 10 min sample. No levers were present at this stage. The same pattern of presentation was subsequently repeated with the clicker stimulus for 30 min. A $90 \mathrm{~min}$ self-administration session under a second-order fixed interval schedule FI20 min(FR10:S) was then commenced. No priming injections were ever given. In this newly introduced schedule, animals received a cocaine infusion on the completion of the first FR10 responses made after a fixed interval of $20 \mathrm{~min}$ had elapsed. The animals could thus self-administer a maximum of four cocaine inf usions within $90 \mathrm{~min}$. The first interval under this schedule (the first $20 \mathrm{~min}$ into the selfadministration session) represented cocaine-seeking behavior under the control of conditioned reinforcers before the first self-administration of cocaine, whereas subsequent intervals represented cued cocaine-seeking behavior under the influence of the drug. At the end of the session, the levers were retracted, and the house light was extinguished. Nine further samples were taken for baseline levels to be re-established, and then $\mathrm{CS}+$ and $\mathrm{CS}-$ presentations were given in reverse order, and a further six samples were collected. Sampling continued for another $30 \mathrm{~min}$. On completion of testing, animals were returned to their home cages.

HPLC procedure. DA was determined in dialysate samples by HPLC and electrochemical detection. Separation was achieved using a Hypersil analytical column (HPLC Technology, Welwyn Garden City, UK; $100 \times$ $4.6 \mathrm{~mm}$ octadecyl silica $3 \mu \mathrm{m}$ ) and a mobile phase consisting of $8.82 \mathrm{gm} / 1$ trisodium citrate, $2.03 \mathrm{gm} / 1 \mathrm{NaH}_{2} \mathrm{PO}_{4}, 500 \mathrm{mg} / 1$ sodium-L-octane sulfonic acid, $22.5 \%$ methanol, $25 \mathrm{mg} / 1$ EDTA, and $1 \mathrm{ml} / 1$ triethylamine, $\mathrm{pH}$ 2.7 , adjusted using orthophosphoric acid. DA was detected by oxidation using a Coulochem II detector equipped with a guard cell $(+300 \mathrm{mV})$ and a dual electrode analytical cell (ESA 5014; E1 $=-150 \mathrm{mV}, \mathrm{E} 2=$ $+150 \mathrm{mV}$ ). Chromatographic data were acquired and processed using Gyncosoft V4.4. The system was calibrated using external standards 


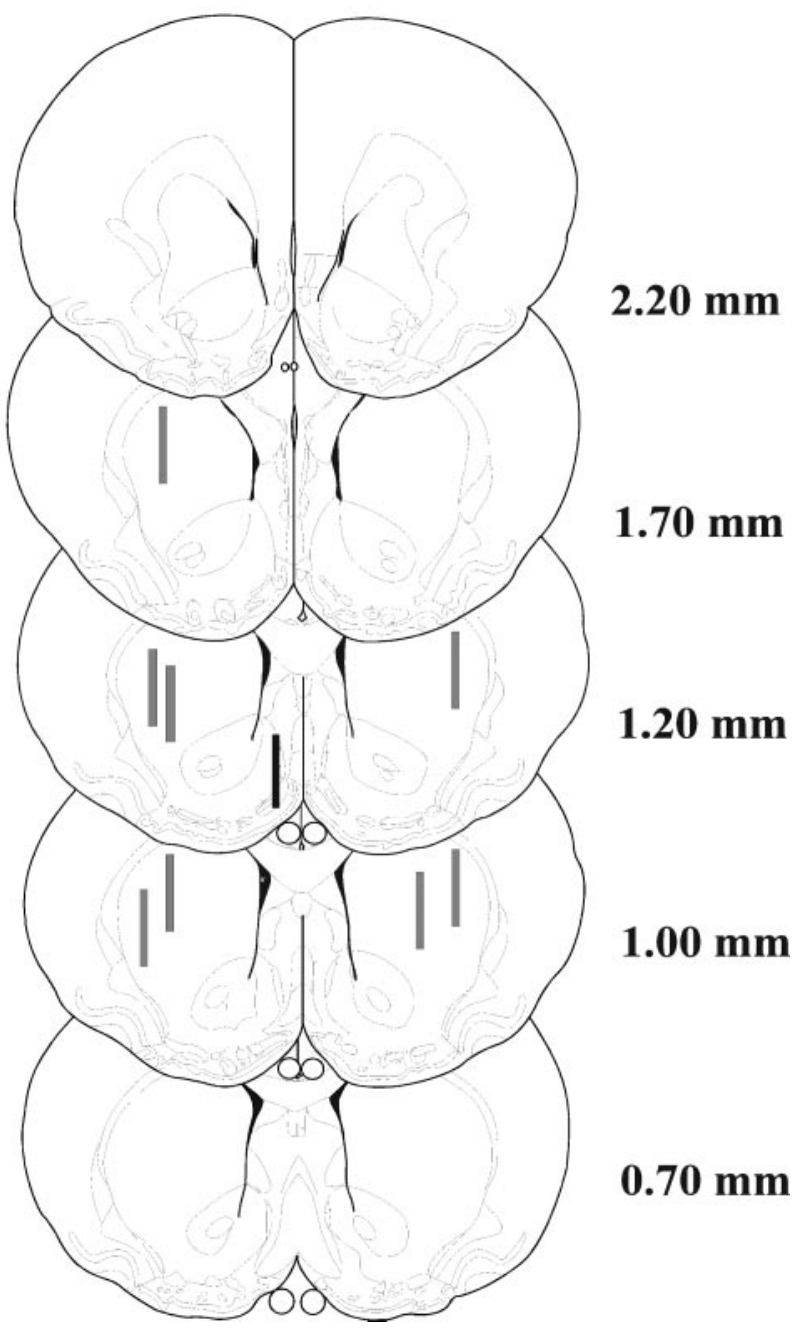

Figure 2. Schematic representation of the locations of the $2 \mathrm{~mm}$ dialysis probe membrane within the dorsal striatum $(n=8)$. Distances shown are in millimeters forward to bregma (adapted from Paxinos and Watson, 1998).

(Sigma) dissolved in aCSF. The detection limit of DA in aqueous standards was $\sim 2 \mathrm{fmol}$ on column.

Histological assessment of microdialysis probe placements. Within a week after the completion of the testing, rats were deeply anesthetized with Euthatal (sodium pentobarbitone, $200 \mathrm{mg} / \mathrm{ml}$ ) and perfused with $0.9 \%$ PBS followed by $4 \%$ paraformaldehyde (PFA) in PBS. Brains were then removed, stored in PFA, and transferred to a $20 \%$ sucrose cryoprotectant solution the day before sectioning. Coronal sections $(60 \mu \mathrm{m})$ of the brain were cut and stained with cresyl violet for verification of probe placement.

Data analysis. All analyses were conducted using GBStat (version 3.0; Dynamics Microsystems Inc, 1997). Behavioral data were expressed as (1) cumulative rate of responding during the self-administration period or (2) the number of responses on the active and inactive lever during each of the four fixed intervals. A two-way repeated measures ANOVA with lever (active and inactive) and interval (four levels) as withinsubjects factors was then conducted.

A one-way ANOVA was conducted on the raw neurochemical data, with time as the repeated measure. Post hoc multiple comparisons were conducted using the Bonferroni $t$ test (versus the final basal sample).

\section{RESULTS}

\section{Histological assessment of dialysis probe locations}

Figure 2 shows a schematic representation of the location of the $2 \mathrm{~mm}$ dialysis probes within the central to lateral parts of the
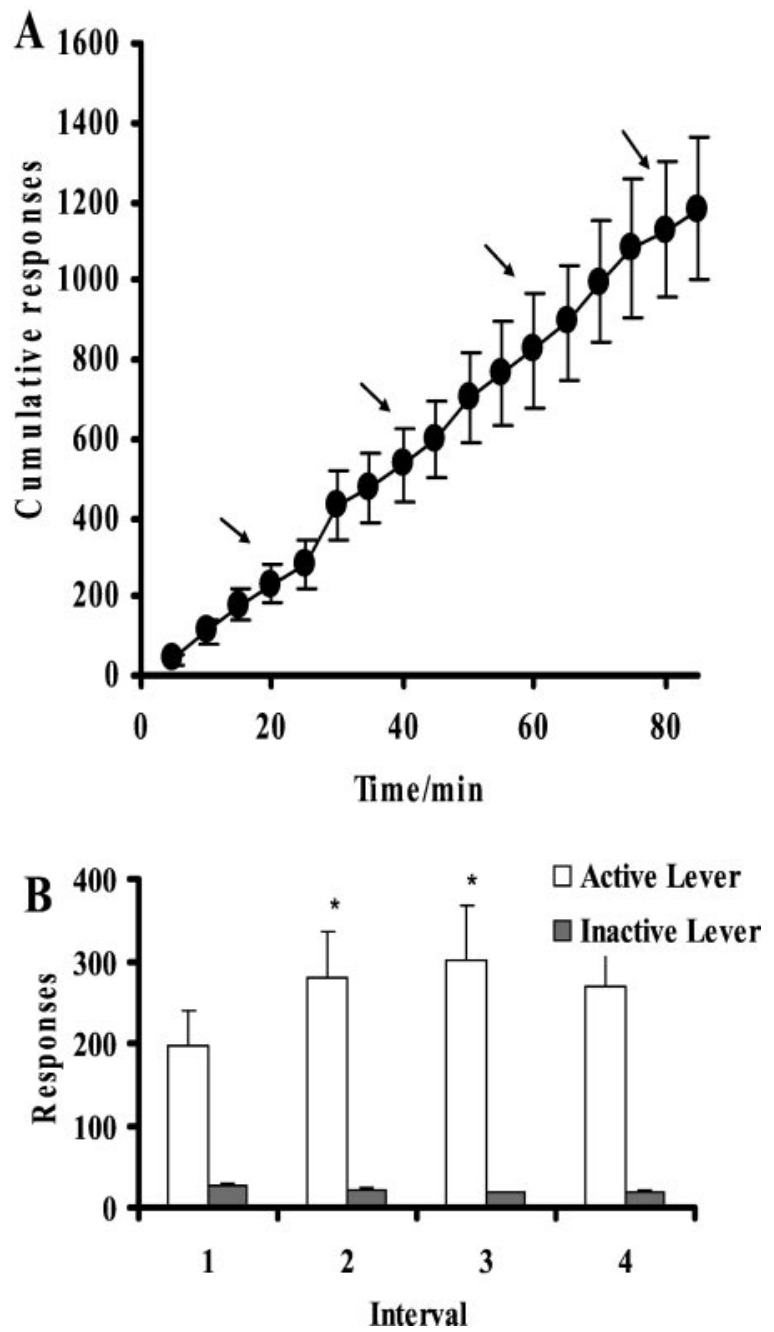

Figure 3. A, Cumulative response records during the period of responding under a second-order FI20 min(FR10:S) schedule, before (first interval) and after (second interval) the self-administration of cocaine. The arrow denotes the delivery of cocaine inf usion $(0.25 \mathrm{mg} /$ inf usion $)$, which was paired with a $20 \mathrm{sec} C S+$ presentation. $B$, Responses on active and inactive levers before (interval 1) and after (intervals 2-4) the selfadministration of cocaine $\left({ }^{*} p<0.05\right)$.

anterior dorsal striatum. No subjects were discarded after assessment of probe placements $(n=8)$.

\section{Behavioral data}

Figure $3 A$ shows the mean rate of lever pressing during the $90 \mathrm{~min}$ session under a FI20(FR10:S) schedule of reinforcement, in which every $10^{\text {th }}$ lever press was accompanied by a brief contingent 2 sec CS + presentation. Intravenous cocaine was delivered on completion of the first 10 lever responses after a fixed interval of $20 \mathrm{~min}$. All animals received the maximum number of infusions (four) within $90 \mathrm{~min}$. The bottom panel of Figure 3 shows the mean number of responses made on the active and inactive levers during each of the four intervals, in which the first interval represents a period of drug-free cocaine-seeking behavior, whereas the second interval reflects cocaine-seeking behavior under the influence of the first cocaine infusion. As shown in Figure $3 B$, responding on the inactive lever was significantly lower than that on the active lever (lever: $F_{(1,48)}=32.26, p=0.0001$; lever $\times$ interval interaction: $\left.F_{(3,42)}=3.21, p=0.03\right)$. Separate 
analysis of active and inactive lever responses revealed a significant increase in responding on the active lever during the second and third intervals, compared with the first interval $\left(F_{(3,24)}=\right.$ 3.03; $p=0.04)$.

\section{Neurochemical data}

The basal level of DA in the dorsal striatum, taken as the mean \pm $\mathrm{SEM}$ fmol/10 min of the first six samples collected, was $13.37 \pm$ $2.54(n=8)$. Mean changes in extracellular DA levels are shown in Figure 4. ANOVA revealed significant changes in the extracellular DA levels over the course of the experiment $\left(F_{(38,266)}=\right.$ 4.09; $p=0.001$ ).

\section{Noncontingent CS+ and CS- presentations}

The first set of noncontingent presentations of the cocaineassociated light $\mathrm{CS}+$ and non cocaine-associated $\mathrm{CS}-$ at time points $0-50$ min failed to alter DA levels in the dorsal striatum. Similarly, reversed presentations of these stimuli in the final phase of the procedure were not accompanied by significant changes in extracellular DA levels.

\section{CS+ presentation contingent on cocaine-seeking behavior}

The first $20 \mathrm{~min}$ of the self-administration session (time points 60 and $70 \mathrm{~min}$ ) allowed the measurement of changes in DA during cocaine-seeking behavior maintained by the CS + contingent on lever pressing, unconfounded by any pharmacological effects of cocaine. As shown in Figure 4, during this cocaine-free, cocaineseeking period, a significant increase in extracellular DA levels, reaching up to $270 \%$ of baseline values at time point $70 \mathrm{~min}$, was observed $(p<0.05)$.

\section{Cocaine self-administration with response-contingent CS+ presentations}

After the first cocaine infusion shortly after $90 \mathrm{~min}$, extracellular DA levels showed a gradual but significant increase, peaking $\sim 310 \%$ above baseline levels and stayed relatively constant for the remaining duration of the self-administration session. Bonferroni $t$ tests revealed that DA levels at 130 and 140 min were significantly different from the final baseline sample $(p=0.01)$.

\section{Combined neurochemical and behavioral data}

Figure 5 shows the mean number of responses made on the active lever within each $10 \mathrm{~min}$ sample during the $90 \mathrm{~min}$ session and the corresponding changes (percentage of baseline) in the levels of extracellular dorsal striatal DA across all animals. The changes in extracellular DA did not follow the pattern of increases in responding on the active lever during cocaine-seeking in the drugfree period (first two samples) or during the subsequent intervals after cocaine had been self-administered.

\section{DISCUSSION}

The present experiment revealed that there was a significant increase in DA efflux in the dorsal striatum during cocaineseeking and response-contingent presentations of the cocaineassociated $\mathrm{CS}+$ before cocaine self-administration. This increased DA efflux was sustained throughout the remaining period of the session in which cocaine was self-administered. However, noncontingent presentations of the cocaine-associated $\mathrm{CS}+$ were not associated with any changes in DA efflux.

\section{Unconditioned effects of cocaine}

The significant increase in DA accompanying the cocaine selfadministration period clearly confirms the often underestimated
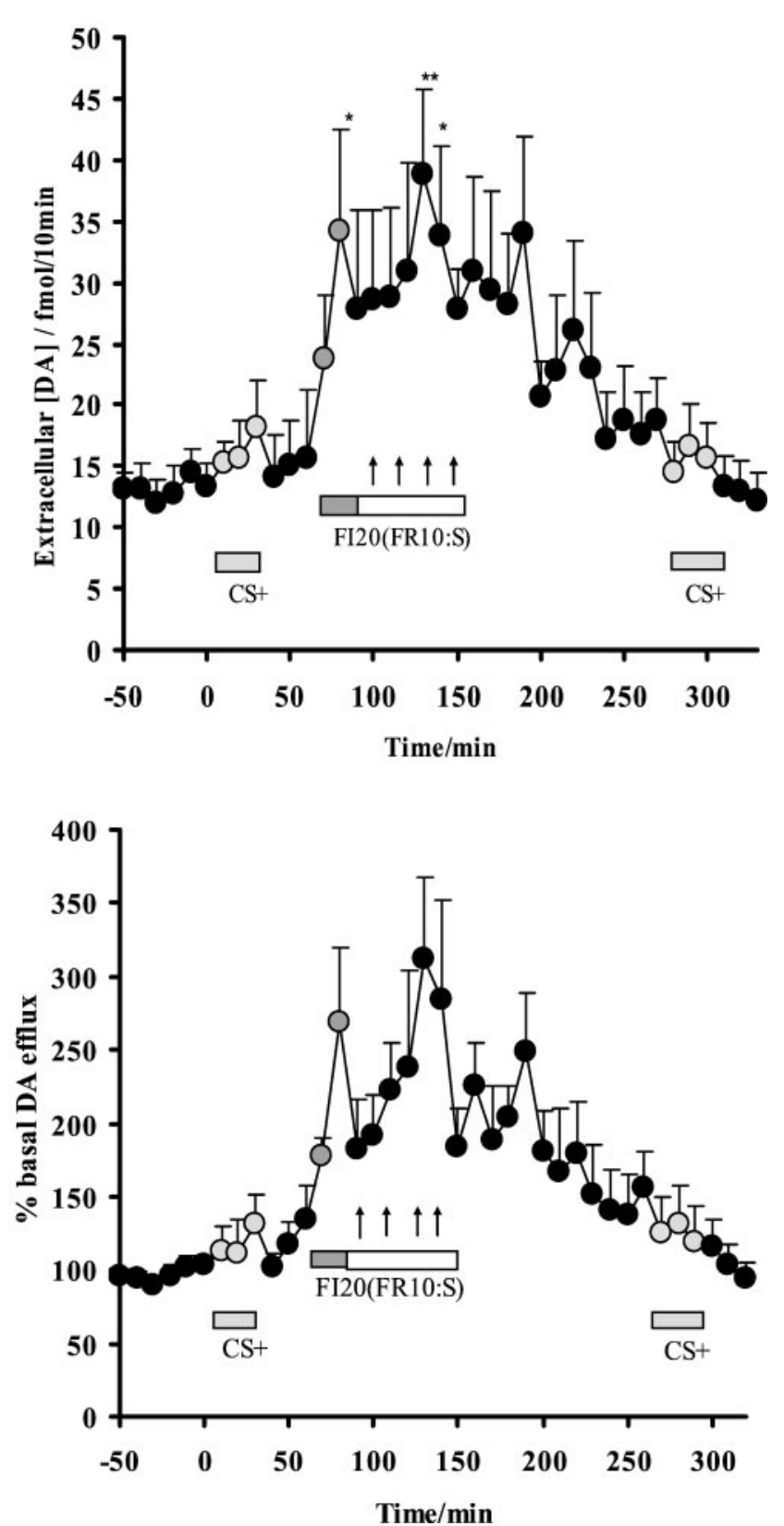

Figure 4. Mean changes in extracellular DA levels expressed as absolute levels (top) and percentage of baseline \pm SEM (bottom). No significant changes in extracellular DA were seen during the first, or the second, noncontingent $\mathrm{CS}+$ presentations (gray shading). A significant elevation in DA levels $\left({ }^{*} p<0.05\right)$ compared with baseline levels was observed during the first $20 \mathrm{~min}$ of the self-administration session, which provided a measure of drug-seeking behavior contingent on CS + presentations, unaffected by cocaine itself (dark gray shading). The ensuing cocaine self-administration period was accompanied by significant, sustained increases in extracellular DA levels $\left({ }^{*} p<0.05 ;{ }^{* *} p<0.01\right)$, with the arrows representing the time points of cocaine infusions.

involvement of the DA innervation of the dorsal striatum in the unconditioned neurochemical effects of cocaine, as reported after experimenter-administered drugs of abuse (Di Chiara and Imperato, 1988; Carboni et al., 1989; Barrot et al., 1999; Wu et al., 2001). The magnitude of the DA increase in the dorsal striatum in the present study was higher overall (in the range of $180-300 \%$ of baseline) than the DA response seen previously in the NAcc core subregion (150-250\%), but smaller compared with the DA 


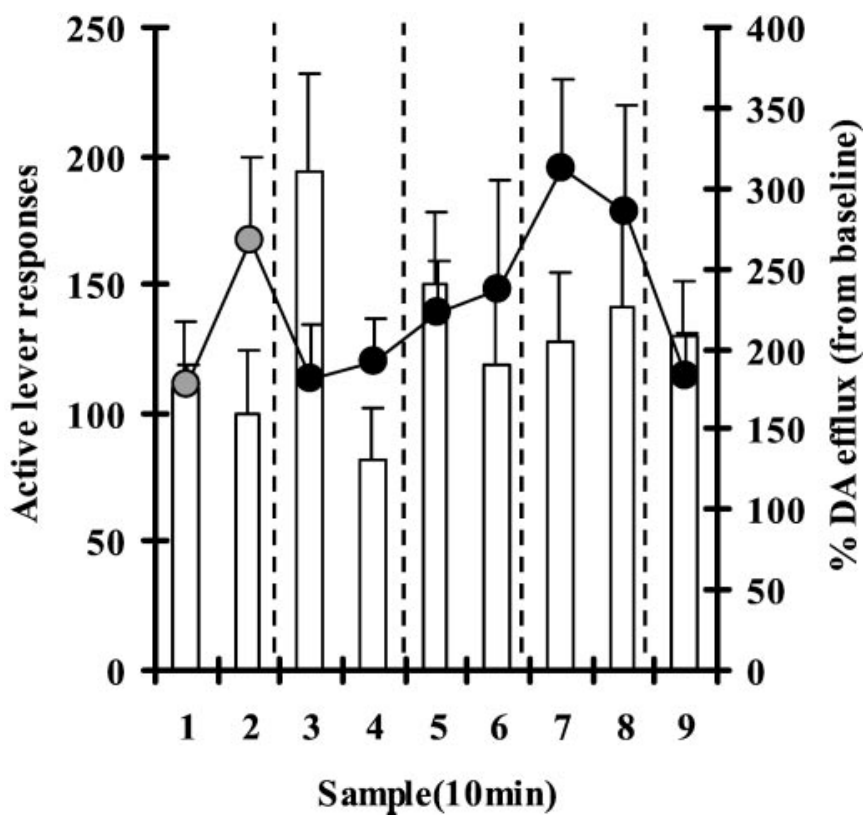

Figure 5. Mean number of responses made on the active lever ( \pm SEM), compared with the pattern of percentage of DA increase in the dorsal striatum ( \pm SEM) in each $10 \mathrm{~min}$ sample, for the duration of the $90 \mathrm{~min}$ cocaine self-administration. The first two samples represent cocaineseeking in the drug-free period, whereas samples 3-9 represent cocaineseeking after cocaine self-administration under the FI20 min(FR10:S) schedule of reinforcement.

\section{NAcc shell NAcc core D striatum}

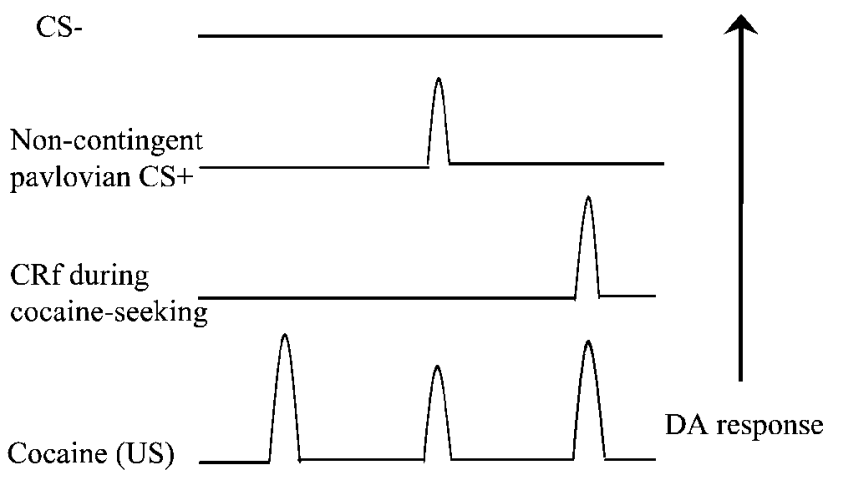

Figure 6. A schematic diagram showing the magnitude of the increase in extracellular DA in the NAcc shell, NAcc core, and dorsal $(D)$ striatum in response to clicker( $\mathrm{CS}-$ ), noncontingent Pavlovian $\mathrm{CS}+$ presentations, cocaine-seeking maintained by conditioned reinforcers, and cocaine self-administration.

response in the NAcc shell (200-330\%) (Ito et al., 2000) (Fig. 6), where psychostimulants and other drugs of abuse are known to have preferential neurochemical effects (Pontieri et al., 1995; David et al., 1998; Cadoni and Di Chiara, 1999). These results are not entirely consistent with previous observations that the increase in cocaine-induced DA levels in vivo is inversely related to the DA reuptake site densities in different regions of the striatum, being highest in the dorsal striatum and lowest in the shell (Marshall et al., 1990; Jones et al., 1996). Neither are they consistent with the finding that the percentage (\%) increase in DA levels in the dorsal striatum was lower than in the NAcc core and shell (Barrot et al., 1999). It is possible that the self-administration of cocaine used in the present study, as opposed to a noncontingent, experimenter administration procedure used in many earlier studies, contributed to the greater increase in DA levels in the dorsal striatum, just as has been found with DA responses in the NAcc (Hemby et al., 1997). The effects of self-administered cocaine on dorsal striatal DA have not been demonstrated previously in rats. However, self-administered cocaine in monkeys has been shown to increase extracellular DA levels in all functional subdivisions of the striatum, but the extent of the DA increase was found to be largest in its ventromedial area, whereas also differing according to the length of exposure to cocaine (Bradberry, 2000; Bradberry et al., 2000). Similarly, it has recently been found that the pattern and density of DA transporter (DAT) binding sites in the monkey striatum show clear changes related to the duration of cocaine self-administration experience, with a progressive spread of DAT binding density from the ventral striatum to more dorsal striatal regions with longer exposure to cocaine (Letchworth et al., 2001).

\section{Drug-seeking behavior}

In contrast with the results reported previously in the NAcc (Ito et al., 2000), a significant increase in extracellular DA levels was observed in the dorsal striatum during active cocaine-seeking behavior maintained by a cocaine-associated conditioned reinforcer. Although no studies have previously directly investigated the role of the dorsal striatum in drug-seeking behavior in rats, rewarded operant responding has been shown to be markedly affected by intradorsal striatal DA receptor antagonism (Phillips et al., 1991; Beninger and Ranaldi, 1993), lateral striatal DA (Salamone et al., 1993; Cousins and Salamone, 1996), and dorsal striatal DA depletion (Robbins et al., 1990). In monkeys, however, Bradberry et al., (2000) failed to observe any increases in ventromedial and central striatal DA during cocaine-seeking behavior in the presence of a discriminative stimulus. The different results from the two studies may have arisen for a variety of reasons, including the quite different ways of presenting the cocaine-associated stimulus, as well as species and neuroanatomical differences.

\section{Motor performance related changes in DA}

The dorsal striatal DA release observed during responding on the active cocaine-seeking lever may be related to the motoric aspects of the behavior. It has been suggested that dorsal striatal DA mediates the establishment of a "response set", which includes diverse representations of such response parameters as which limb to use, which side of space to respond, the timing of the response, and the force to be applied (Robbins and Everitt, 1992). This is consistent with much evidence of a role for dorsal striatal DA in various aspects of motor behavior (Ungerstedt, 1971; Carli et al., 1985; Fairley and Marshall, 1986; Pisa and Cyr, 1990; Robbins and Everitt, 1992; Salamone et al., 1993). However, the DA increase during cocaine-seeking in the present study is unlikely to be an index of motor performance alone. Kilpatrick et al. (2000) showed a significant increase in extracellular DA levels in the dorsal striatum in response to experimenter-delivered intracranial electrical stimulations and in the initial stages of acquisition of intracranial self stimulation, but not during performance of the response-contingent stimulation, suggesting that responding per se is not necessary for the induction of a dorsal striatal DA response. Although the absence of changes in DA release during lever-pressing performance under a FI $30 \mathrm{sec}$ schedule of food reinforcement in the ventrolateral striatum has previously been 
reported (Cousins et al., 1999), changes in dorsal striatal DA release during reward-related lever pressing has not been directly studied. However, Eagle et al. (1999) found that dorsal striatal lesions had little effect on the rate of lever pressing for food under a progressive ratio schedule, suggesting that striatal lesions may leave the performance of tasks that require homogenous, repetitive responding intact.

\section{Expectation of reward}

The increased extracellular DA levels in the dorsal striatum observed here during cocaine-seeking could be related to the "expectation" of reward. Expectation-related activity in the period preceding target instruction cues and reward delivery has been consistently observed in substantia nigra DA neurons projecting to the dorsal striatum of primates (Hikosaka et al., 1989; Alexander and Crutcher, 1990). Additionally, using a delayed go-no go task, Apicella et al. (1992) demonstrated the responsiveness of a large number of striatal neurons (both dorsal and ventral) to the preparatory aspects, as well as execution, of a visually guided, reward-seeking movement. Whether the expectation- and preparation-related activations of striatal neurons represent motivational or motoric response selection processes is unclear, especially in view of the fact that ventral striatal neurons are just as, if not more, responsive in general to the preparatory aspects of behavior (Schultz et al., 1992; Schultz, 1998). However, it is unlikely that such preparatory dopamine activity in the dorsal striatum has a motivational basis, because dorsal striatal lesions have no major effects on measures of motivation (e.g., the break point and postreinforcement pause) under a progressive ratio schedule, even when other motivational factors such as the levels of food deprivation or magnitude of reinforcement are manipulated (Eagle et al., 1999).

\section{Pavlovian conditioning, conditioned reinforcement, and striatal DA}

The DA response in the dorsal striatum in the present study was specific to the presentation of the $\mathrm{CS}+$ as a conditioned reinforcer during active cocaine-seeking and not to noncontingent presentations of the Pavlovian CS + alone. In contrast, presentations of a cocaine-associated CS + alone evoked a selective increase in DA levels in the NAcc core region (Ito et al., 2000). Thus, these results do not support the notion that all DA projections to the striatum (dorsal and ventral) are invariably activated by the unexpected presentation of Pavlovian cues (Schultz et al., 1993, 1997). We have instead demonstrated a clear distinction between the DA correlates in different striatal regions during noncontingent presentations of a Pavlovian cue, as well as during cocaine-seeking behavior under the control of a drug-associated conditioned reinforcer (Fig. 6).

It is suggested that responding under the second-order schedule of reinforcement used here had developed S-R habitual qualities on the basis of (1) the progressive increase in responsereinforcement ratios and the consequentially greater control by the conditioned reinforcer and (2) extended training. The progression from the acquisition to maintenance stages of cocaineseeking behavior may involve a shift in the underlying neural substrate as the control over the behavior is devolved from the ventral to dorsal striatum. Thus, the NAcc core DA system may be involved in subserving the invigorating and response-eliciting effects of a CS + on drug-seeking behavior during the acquisition of the light $\mathrm{CS}$-cocaine association (Everitt et al., 2001). However, once established, other neurochemical systems, including the DA innervation of the dorsal striatum, may take precedence in subserving cocaine-seeking behavior maintained by a CS+ acting as a conditioned reinforcer (Robbins and Everitt, 1999; Everitt et al., 2001). Moreover, monkeys self-administering cocaine over periods of either $5 \mathrm{~d}, 12$ weeks, or 1.5 years showed an increase in the levels of DA transporter binding sites that also revealed a ventral (accumbens) to dorsal striatal progression at the longest time period (Letchworth et al., 2001). Such data and those in the present study thus extend the hypothesis that different striatal regions subserve differential, although related functional processes. They also lend support to recent anatomical evidence that has indicated that the interactions between the subregions of the striatum may be organized in a spiral manner, with the corticostriatal loop including the NAcc shell influencing the output of the NAcc core, whereas the NAcc core circuitry in turn influences information passing through the dorsal striatum (Haber et al., 2000). In this way, chronically self-administered cocaine may "consolidate" habitual drug-seeking behavior via long-term neuroadaptations (Nestler, 2001) in these corticostriatal loops (Robbins and Everitt, 1999; Everitt et al., 2001).

\section{REFERENCES}

Alexander GE, Crutcher MD (1990) Preparation for movement: neural representations of intended direction in three motor areas of the monkey. J Neurophysiol 64:133-150.

Altman J, Everitt BJ, Glautier S, Markou A, Nutt D, Oretti R, Phillips GD, Robbins TW (1996) The biological, social and clinical bases of drug addiction: commentary and debate. Psychopharmacology 125:285-345.

Apicella P, Scarnati E, Ljungberg T, Schultz W (1992) Neuronal activity in monkey striatum related to the expectation of predictable environmental events. J Neurophysiol 68:945-960.

Barrot M, Marinelli M, Abrous DN, Rouge-Pont F, Le Moal M, Piazza PV (1999) Functional heterogeneity in dopamine release and in the expression of Fos-like proteins within the rat striatal complex. Eur J Neurosci 11:1155-1166.

Beninger RJ, Ranaldi R (1993) Microinjections of flupenthixol into the caudate-putamen but not the nucleus accumbens, amygdala or frontal cortex of rats produce intra-session declines in food-rewarded operant responding. Behav Brain Res 55:203-212.

Bradberry CW (2000) Acute and chronic dopamine dynamics in a nonhuman primate model of recreational cocaine use. J Neurosci 20:7109-7115.

Bradberry CW, Barrett-Latimore R, Jatlow P, Rubino SR (2000) Impact of self-administered cocaine and cocaine cues on extracellular dopamine in mesolimbic and sensorimotor striatum in rhesus monkeys. J Neurosci 20:3874-3883.

Cadoni C, Di Chiara G (1999) Reciprocal changes in dopamine responsiveness in the nucleus accumbens shell and core and in the dorsal caudate-putamen in rats sensitized to morphine. Neuroscience 90:447-455

Caine SB, Lintz R, Koob GF (1992) Intravenous self-administration techniques in animals. In: Behavioral neuroscience: a practical approach (Sahgal A, ed), pp 117-143. Oxford: IRL.

Carboni E, Imperato A, Perezzani L, Di Chiara G (1989) Amphetamine, cocaine, phencyclidine and nomifensine increase extracellular dopamine concentrations preferentially in the nucleus accumbens of freely moving rats. Neuroscience 28:653-661.

Carli ME, Evenden JL, Robbins TW (1985) Depletion of unilateral striatal dopamine impairs initiation of contralateral actions and not sensory attention. Nature 313:679-682.

Childress AR, McLellan AT, Ehrman R, O’Brien CP (1988) Classically conditioned responses in opioid and cocaine dependence: a role in relapse? NIDA Res Monogr 84:25-43.

Childress AR, Hole AV, Ehrman RN, Robbins SJ, McLellan AT, O’Brien CP (1993) Cue reactivity and cue reactivity interventions in drug dependence. NIDA Res Monogr 137:72-95.

Cousins MS, Salamone JD (1996) Skilled motor deficits in rats induced by ventrolateral striatal dopamine depletions: behavioral and pharmacological characterization. Brain Res 732:186-194.

Cousins MS, Trevitt J, Atherton A, Salamone JD (1999) Different behavioral functions of dopamine in the nucleus accumbens and ventrolateral striatum: a microdialysis and behavioral investigation. Neuroscience 91:925-934.

David DJ, Zahniser NR, Hoffer BJ, Gerhardt GA (1998) In vivo electrochemical studies of dopamine clearance in subregions of rat nucleus 
accumbens: differential properties of the core and shell. Exp Neurol $153: 277-286$

Di Chiara GD, Imperato A (1988) Drugs abused by humans preferentially increase synaptic dopamine concentrations in the mesolimbic system of freely moving rats. Proc Natl Acad Sci USA 85:5274-5278.

Eagle DM, Humby T, Dunnett SB, Robbins TW (1999) Effects of regional striatal lesions on motor, motivational, and executive aspects of progressive-ratio performance in rats. Behav Neurosci 113:718-731.

Edwards G, Gross MM (1976) Alcohol dependence: provisional description of a clinical syndrome. Br Med J 1:1058-1061.

Everitt BJ, Dickinson A, Robbins TW (2001) The neuropsychological basis of addictive behavior. Brain Res Rev 36:129-138.

Fairley PC, Marshall JF (1986) Dopamine in the lateral caudateputamen of the rat is essential for somatosensory orientation. Behav Neurosci 100:652-663.

Haber SN, Fudge JL, McFarland NR (2000) Striatonigrostriatal pathways in primates from an ascending spiral from the shell to the dorsolateral striatum. J Neurosci 20:2369-2382.

Hemby SE, Co C, Koves TR, Smith JE, Dworkin TR (1997) Differences in extracellular dopamine concentrations in the nucleus accumbens during response-dependent and response-independent cocaine administration in the rat. Psychopharmacology 133:7-16.

Hikosaka O, Sakamoto M, Usui S (1989) Functional properties of monkey caudate neurons. III. Activities related to expectation of target and reward. J Neurophysiol 61:814-832.

Ito R, Dalley JW, Howes SR, Robbins TW, Everitt BJ (2000) Dissociation in conditioned dopamine release in the nucleus accumbens core and shell in response to cocaine cues and during cocaine-seeking behavior in rats. J Neurosci 20:7489-7495.

Jones SR, O'Dell SJ, Marshall JF, Wightman RM (1996) Functional and anatomical evidence for different dopamine dynamics in the core and shell of the nucleus accumbens in slices of rat brain. Synapse 23:224-231.

Kilpatrick MR, Rooney MB, Michael DJ, Wightman RM (2000) Extracellular dopamine dynamics in rat caudate-putamen during experimenter-delivered and intracranial self-stimulation. Neuroscience 96:697-706.

Leshner AI (1997) Addiction is a brain disease, and it matters. Science 278:45-47.

Letchworth SR, Nader MA, Smith HR, Friedman DP, Porrino LJ (2001) Progression of changes in dopamine transporter binding site density as a result of cocaine self-administration in rhesus monkeys. $\mathbf{J}$ Neurosci 21:2799-2807.

Marshall JF, O’Dell SJ, Navarette R, Rosenstein AJ (1990) Dopamine high-affinity transport site topography in rat brain: major differences between dorsal and ventral striatum. Neuroscience 37:11-21.

Mishkin M, Malamut B, Bachevalier J (1984) Memories and habits: Two neural systems. In: Neurobiology of human learning and memory (Lynch G, McGaugh JL, Weinberger NM, eds), pp 65-77. New York: Guilford.

Nestler EJ (2001) Molecular basis of long-term plasticity underlying addiction. Nat Rev Neurosci 2:119-128.

Niaura RS, Rohsenow DJ, Binkoff JA, Monti PM, Pedraza M, Abrams DB (1988) Relevance of cue reactivity to understanding alcohol and smoking relapse. J Abnorm Psychol 97:133-152.

O'Brien CP (1997) A range of research-based pharmacotherapies for addiction. Science 278:66-70.
O’Brien CP, Childress AR, McLellan AT, Ehrman R, Ternes JW (1988) Types of conditioning found in drug-dependent humans. NIDA Res Monogr 84:44-61.

O'Brien CP, Childress AR, Ehrman R, Robbins SJ (1998) Conditioning factors in drug abuse: can they explain compulsion? J Psychopharmacol $12: 15-22$.

Packard MG, White NM (1991) Dissociation of hippocampal and caudate nucleus memory systems by post-training intracerebral injection of dopamine agonists. Behav Neurosci 105:295-306.

Paxinos G, Watson C (1998) The rat brain in stereotaxic coordinates, Ed 4. San Diego: Academic.

Phillips G, Willner P, Muscat R (1991) Anatomical substrates for neuroleptic-induced reward attenuation and neuroleptic-induced response decrement. Behav Pharmacol 2:129-141.

Pisa M, Cyr J (1990) Regionally selective roles of the rat's striatum in modality-specific discrimination learning and forelimb reaching. Behav Brain Res 37:281-292.

Pontieri FE, Tanda G, Di Chiara G (1995) Intravenous cocaine, morphine and amphetamine preferentially increase extra-cellular dopamine in the "shell" as compared with the "core" of the rat nucleus accumbens. Proc Natl Acad Sci USA 92:12304-12308.

Reading PJ, Dunnett SB, Robbins TW (1991) Dissociable roles of ventral, medial and lateral striatum on the acquisition and performance of complex visual stimulus-response habit. Behav Brain Res 45:147-161.

Robbins TW, Everitt BJ (1992) Functions of dopamine in the dorsal and ventral striatum. Semin Neurosci 4:119-127.

Robbins TW, Everitt BJ (1999) Drug addiction: bad habits add up. Nature 398:567-570.

Robbins TW, Giardini V, Jones GH, Reading P, Sahakian BJ (1990) Effects of dopamine depletion from the caudate-putamen and nucleus accumbens septi on the acquisition and performance of a conditional discrimination task. Behav Brain Res 38:243-261.

Salamone JD, Mahan K, Rogers S (1993) Ventrolateral striatal dopamine depletions impair feeding and food handling in rats. Pharmacol Biochem Behav 44:605-610.

Schultz W (1998) Predictive reward signal of dopamine neurons. J Neurophysiol 80:1-27.

Schultz W, Apicella P, Scarnati F, Ljungberg T (1992) Neuronal activity in monkey ventral striatum related to the expectation of reward. J Neurosci 12:4595-4610.

Schultz W, Apicella P, Ljungberg T (1993) Responses of monkey dopamine neurons to reward and conditioned stimuli during successive steps of learning a delayed response task. J Neurosci 13:900-913.

Schultz W, Dayan P, Montague P (1997) A neural substrate of prediction and reward. Science 275:1593-1598.

Tiffany ST, Carter BL (1998) Is craving the source of compulsive drug use? J Psychopharmacol 12:23-30.

Ungerstedt U (1971) Postsynaptic supersensitivity after 6-hydroxydopamine induced degeneration of the nigro-striatal dopamine system. Acta Physiol Scand Suppl 367:69-93.

White NM (1989) Reward or reinforcement: What's the difference? Neurosci Biobehav Rev 13:181-186.

Wu Q, Reith EA, Kuhar MJ, Carroll FI, Garris PA (2001) Preferential increase in nucleus accumbens dopamine after systemic cocaine administration are caused by unique characteristics of dopamine neurotransmission. J Neurosci 21:6338-6347. 